Review

\title{
Anticancer Activity of Essential Oils and Other Extracts from Aromatic Plants Grown in Greece
}

\author{
Eleni Fitsiou 1,2 1 and Aglaia Pappa ${ }^{1, *}$ \\ 1 Department of Molecular Biology and Genetics, Democritus University of Thrace, University Campus, \\ Dragana, 68100 Alexandroupolis, Greece \\ 2 European Research Institute for the Biology of Ageing, University Medical Center Groningen, \\ University of Groningen, Antonius Deusinglaan 1, 9713 AV Groningen, The Netherlands \\ * Correspondence: apappa@mbg.duth.gr
}

Received: 30 June 2019; Accepted: 2 August 2019; Published: 7 August 2019

check for updates

\begin{abstract}
Aromatic plants have a long and significant history in the traditional medicine of many countries. Nowadays, there is an increasing interest in investigating the biological properties of aromatic plant extracts mainly due to their diversity, high availability, and low toxicity. Greece is abundant in aromatic plants, which can be attributed to the country's geographical position, the morphology of its landscape, and its numerous mountainous and insular areas. In the past 15 years, a number of aromatic plant extracts of Greek origin have been studied for their bioactivities, including their antiproliferative potential against different types of cancer. Although the pharmacological activities of specific species of Greek origin have been reviewed before, no gathered information on explicitly Greek species exist. In this review, we summarize existing data on the antiproliferative activity of extracts isolated from Greek aromatic plants and discuss their molecular mode(s) of action, where available, in order to identify promising extracts for future research and link chemical constituents responsible for their activity. We conclude that essentials oils are the most frequently studied plant extracts exhibiting high diversity in their composition and anticancer potential, but also other extracts appear to be worthy of further investigation for cancer chemoprevention.
\end{abstract}

Keywords: aromatic plants; natural extracts; Greece; antiproliferative activity; cancer

\section{Introduction}

Aromatic plants take their name from the distinct aroma they produce, which is attributed to a mixture of volatile compounds extracted as essential oils. They constitute $10 \%$ of the plant kingdom $(17,000$ species $)$ and are distributed all over the world, mostly in temperate and warm countries [1]. Greece is abundant in aromatic plants. Its geographical position, the morphology of its landscape, and the numerous mountainous and insular areas (109 out of 225 habitat types encountered in the European Union are found in Greece) [2] contribute to the country's high plant diversity and endemism (6600 species and subspecies) [3], explaining its long-documented ethnopharmacological history. Most of the plants collected for research purposes in the Greek area have been obtained from Central Greece and Crete and belong to the Lamiaceae family [4]. In recent years, increased interest has been focused on studying the biological properties of aromatic plant extracts mostly due to their high availability and few side-effects. Among their reported properties is their ability to affect proliferation of cancer cells and induce apoptosis, one of the most important features of cancer chemoprevention.

In Greece, cancer is the second leading cause of death after cardiovascular diseases. With a population of approximately $11,000,000$, there was an expected number of 67,400 new cancer cases and 33,200 deaths in 2018 ( $\sim 6 \%$ and $3 \%$ of the population, respectively) [5]. Although overall cancer rates have not increased since 2014 ( 29,000 deaths), there has been an increase in the number 
of specific cancer types including lung cancer in men, colorectal, breast, pancreatic, and prostate cancer [6]. According to the International Agency for Research on Cancer (IARC) and the World Cancer Observatory, Greece was in the 28th place in cancer rates globally for men and women in 2018 with lung cancer having the highest rates in incidence and mortality for both sexes (one of the highest rates for men in Europe) followed by breast and colorectal cancer [5,7]. Unfortunately, there are no data available on the correlation between the anticancer activity of aromatic plants and tumor incidence in Greece. It is challenging, though, to investigate how isolated food components may contribute to cancer incidence and/or affect mortality rates as assessing diet through dietary patterns has become popular in diet-disease investigations [8]. However, cancer reports suggest that foods rich in vitamins and phytochemicals can act as chemopreventive agents reducing the risk of various types of cancer, especially colorectal cancer $[9,10]$. In addition, there are studies with Greek participants that show that the adoption of the Mediterranean diet (characterized by high intake of fruit, vegetables, nuts, whole grains, and olive oil; a moderate intake of fish and dairy products; and low intake of meat, especially red meat), reduce cancer-related and total mortality [11,12].

Currently, literature is lacking thorough research on the anticancer activity of aromatic extracts of Greek origin, which would be very useful for the appraisal and comparison of the data in this increasingly growing field. Therefore, the present review summarizes all the existing data on various plant extracts discussing their molecular mode(s) of action where available.

\section{Methods}

We performed a systematic search on Pubmed, Google scholar, and Scopus databases using the keywords "aromatic plants", "plant extracts", "cancer", "antiproliferative", "anticancer", "Greece", "Greek". We focused our research on selected studies dealing only with the activity of aromatic plant extracts and not plants in general or isolated compounds against cancer in vitro and/or in vivo. We also excluded any study were the plant material was not harvested from the Greek area.

\section{Results}

Our research was restricted only to aromatic plant extracts and not plants in general or isolated compounds. We found 28 research studies conducted from 1996 to July 2019, dealing mostly with essential oils and methanolic extracts. In these studies, 48 species were investigated for their properties, the majority of which belong to the Lamiaceae family, in accordance with previous published data [4] (Figure 1a). Only four studies included in vivo models; three of them were investigating Pistacia lentiscus var. Chia extracts and one the essential oil of Origanum Onites L. (Figure 1b). In the majority of these studies, human cancer cells were used to evaluate cytotoxicity, with colon cancer cells being the most frequently used, followed by hepatocellular and breast carcinomas. Finally, only four studies included testing the cytotoxicity on normal cells, too (PBMCs, African green monkey kidney, rabbit skin, mouse adipose areolar, and HaCat cells). The available data are summarized in Table 1. 
(a)

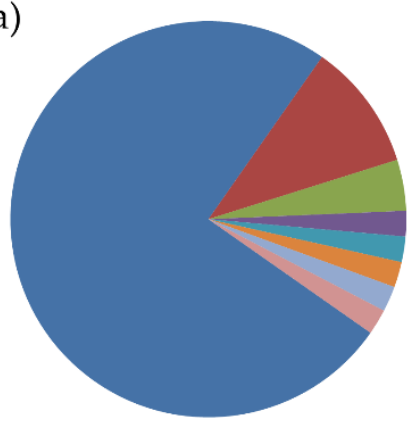

(b)

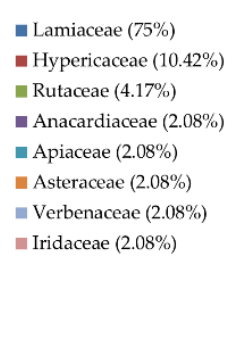

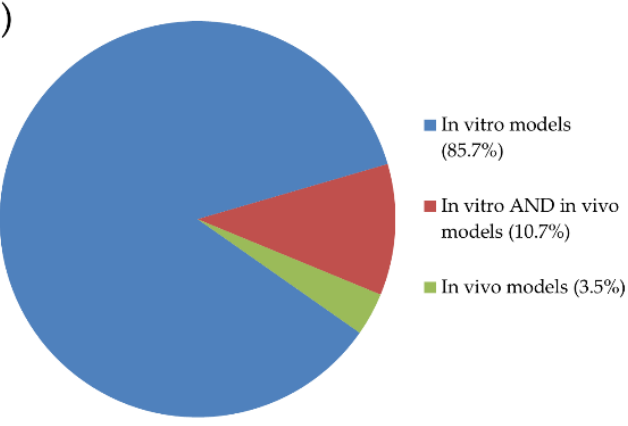

Figure 1. (a) The percentage of plant families of the species studied for their antiproliferative activity. (b) The percentage of studies on aromatic plant extracts performed in (i) in vitro models, (ii) in vitro and in vivo models, or (iii) only in in vivo models.

Pistacia lentiscus var. Chia, commonly known as Chios mastic, is the plant mostly studied (nine studies) and is the only one with available and more detailed information on its molecular mode(s) of action on various cancer models. Pistacia lentiscus var. Chia is a variety endemic to Chios island, with high economic value as it is the only variety that produces resin when its bark is scored. When the essential oil of the resin was incubated with breast, colon, and ovarian adenocarcinoma cell lines (MCF-7, LoVo, 2008) for $3 \mathrm{~h}$, followed by a $21 \mathrm{~h}$ recovery period, it demonstrated the weakest activity compared to other Pistacia species originating from other countries $\left(\mathrm{EC}_{50}>500 \mu \mathrm{g} / \mathrm{mL}\right)$ [13]. The essential oil has been also studied against human leukemic and melanoma cells and mouse lung carcinoma (K562, Lewis lung carcinoma cells, B16, respectively) and also in vivo in a lung cancer mouse model. These studies revealed that mastic oil reduces cell viability and tumor growth. In addition, it was shown that it induces apoptosis in cancer cells, reduces the expression of chemokines, limits their invasive and adhesive potential, and is an inhibitor of angiogenesis via the reduction of VEGF expression and neovascularisation [14-17]. When the oil was tested against colon carcinoma, it showed significant dose- and time-dependent cytotoxicity in vitro and tumor reducing capacity in vivo, which was higher than the activity of its major components, $\alpha$-pinene and myrcene, tested either alone or in combination in the ratio found in the oil mixture. Furthermore, downregulation in the levels of the proliferation markers Ki-67 and survivin and attenuation of cancer cell migration was observed [18]. A hexane and an ethanol extract of mastic have been also studied for their anticancer potential in vitro against a human colon cancer cell line (HCT116) and in vivo in an experimental colon cancer mouse model. Both extracts caused dose-dependent inhibition of cell growth, while the hexane extract also caused tumor growth suppression. Furthermore, the extracts caused G1 cell cycle arrest, induction of apoptosis via the activation of caspases 3,8 and 9, while it was found that the cell death caused by the ethanol extract is independent of p53, Bcl-2, and FADD [19-21]. 
Table 1. Summary of the antiproliferative activity of extracts isolated from Greek aromatic plants. The cell lines are human unless otherwise stated. N.d. = not determined. (-) in major component and collection location columns indicates that the authors report no data on the major components and collection location, respectively. (-) in dose/concentration column indicates that the concentrations used were not reported.

\begin{tabular}{|c|c|c|c|c|c|c|c|c|}
\hline Family & Species & Extract & $\begin{array}{c}\text { Major } \\
\text { Components }\end{array}$ & $\begin{array}{l}\text { Collection } \\
\text { Location }\end{array}$ & Type of Cell & $\begin{array}{c}\text { Dose/ } \\
\text { Concentration }\end{array}$ & Effect & Ref. \\
\hline \multirow{7}{*}{ Anacardiaceae } & \multirow{7}{*}{$\begin{array}{l}\text { Pistacia lentiscus } \\
\text { var. Chia }\end{array}$} & \multirow[t]{2}{*}{ Essential oil } & \multirow[t]{2}{*}{$\begin{array}{l}\alpha \text {-Pinene }(67.71 \%) \\
\text { Myrcene }(18.81 \%)\end{array}$} & \multirow[t]{2}{*}{ Commercial } & $\begin{array}{l}\text { Colon carcinomas Caco2 and } \\
\text { HT-29 } \\
\text { Mouse colon carcinoma } \\
\text { CT-26 }\end{array}$ & $\begin{array}{c}0.000445-0.89 \\
\mathrm{mg} / \mathrm{mL}\end{array}$ & $\begin{array}{c}\text { Caco2 }^{2} \mathrm{EC}_{50} 48 \mathrm{~h}=0.0368 \pm 0.0225 \mathrm{mg} / \mathrm{mL} \\
\mathrm{EC}_{50} 72 \mathrm{~h}=0.0176 \pm 0.0035 \mathrm{mg} / \mathrm{mL} \\
\mathrm{HT}^{-29} \mathrm{EC}_{50} 48 \mathrm{~h}=0.1751 \pm 0.0028 \mathrm{mg} / \mathrm{mL} \\
\mathrm{EC}_{50} 72 \mathrm{~h}=0.0762 \pm 0.0057 \mathrm{mg} / \mathrm{mL} \\
\text { CT26 EC }_{50} 48 \mathrm{~h}=0.1335 \pm 0.054 \mathrm{mg} / \mathrm{mL} \\
\text { EC }_{50} 72 \mathrm{~h}=0.0104 \pm 0.0004 \mathrm{mg} / \mathrm{mL}\end{array}$ & \multirow[t]{2}{*}{ [18] } \\
\hline & & & & & $\begin{array}{l}\text { Colon cancer mouse model } \\
\text { (in vivo) }\end{array}$ & $0.58 \mathrm{~g} / \mathrm{kg}$ b.w. & $\begin{array}{c}44-52 \% \text { tumor volume inhibition } \\
\text { Cancer cell migration attenuation } \\
\text { Downregulation in the expression levels } \\
\text { of Ki-67 and survivin }\end{array}$ & \\
\hline & & Essential oil & $\begin{array}{l}\alpha \text {-Pinene }(72.93 \%) \\
\text { Myrcene }(13.57 \%)\end{array}$ & Commercial & $\begin{array}{c}\text { Ovarian adenocarcinoma } 2008 \\
\text { breast adenocarcinoma MCF-7 } \\
\text { colon carcinoma LoVo }\end{array}$ & - & $\mathrm{EC}_{50}>500 \mu \mathrm{g} / \mathrm{mL}$ & [13] \\
\hline & & Essential oil & - & Commercial & $\begin{array}{c}\text { chronic myelogenous leukemia } \\
\text { K562 } \\
\text { Mouse B16 melanoma }\end{array}$ & $0.01-0.1 \% v / v$ & $\begin{array}{l}\text { K562: Reduction of viability. Induction of } \\
\text { apoptosis; Reduction of VEGF release } \\
\text { levels; Inhibition of endothelial cells } \\
\text { proliferation and neovascularization; } \\
\text { Erk1/2 reduction } \\
\text { B16: Reduction of VEGF release levels }\end{array}$ & [14] \\
\hline & & \multirow{2}{*}{ Essential oil } & \multirow{2}{*}{$\alpha$-Pinene $(\sim 70 \%)$} & \multirow{2}{*}{ Commercial } & Mouse Lewis lung carcinoma & $0.01-0.02 \% v / v$ & $\begin{array}{l}\text { Cell proliferation suppression; VEGF } \\
\text { release reduction; Chemokine release } \\
\text { reduction; GTPases Ras, RhoA and } \\
\text { NF- } k \text { B-dependent reporter gene } \\
\text { expression decrease }\end{array}$ & \multirow[t]{2}{*}{ [16] } \\
\hline & & & & & $\begin{array}{l}\text { Lung cancer mouse model } \\
\text { (in vivo) }\end{array}$ & 45 mg/Kg b.w. & $\begin{array}{c}\text { Tumor growth suppression; Apoptosis } \\
\text { induction; Neovascularization reduction; } \\
\text { Chemokine expression reduction GTPases, } \\
\text { Ras, RhoA and NF- } k \text { B-dependent reporter } \\
\text { gene expression decrease }\end{array}$ & \\
\hline & & Essential oil & - & - & Mouse Lewis lung carcinoma & $0.01 \% v / v$ & $\begin{array}{l}\text { PTEN, E2F7, HMOX1 increase; NOD1 } \\
\text { decrease; Apoptosis induction; } \\
\text { Inflammation decrease }\end{array}$ & [17] \\
\hline
\end{tabular}


Table 1. Cont.

\begin{tabular}{|c|c|c|c|c|c|c|c|c|}
\hline Family & Species & Extract & $\begin{array}{c}\text { Major } \\
\text { Components }\end{array}$ & $\begin{array}{l}\text { Collection } \\
\text { Location }\end{array}$ & Type of Cell & $\begin{array}{c}\text { Dose/ } \\
\text { Concentration }\end{array}$ & Effect & Ref. \\
\hline \multirow{4}{*}{ Anacardiaceae } & & Essential oil & - & Commercial & Mouse Lewis lung carcinoma & $0.01-0.04 \% v / v$ & $\begin{array}{l}\text { Reduction of MMP-2, ICAM-1 and } \\
\text { VCAM-1 expression levels; attenuation of } \\
\text { f-actin fiber formation; limitation of cell } \\
\text { invasiveness; impairment of tumor cell } \\
\text { adhesive interactions and } \\
\text { neovascularization potential }\end{array}$ & [15] \\
\hline & & $\begin{array}{c}\text { Mastic gum } \\
\text { hexane extract }\end{array}$ & Caryophyllene & - & Colon carcinoma HCT116 & $25-100 \mu \mathrm{g} / \mathrm{mL}$ & $\begin{array}{l}\text { Dose-dependent growth inhibition } \\
\text { G1 cell cycle arrest } \\
\text { Induction of apoptosis } \\
\text { Activation of caspases } 3,8,9 \\
\text { PARP degradation }\end{array}$ & [20] \\
\hline & & $\begin{array}{c}\text { Mastic gum } \\
\text { hexane extract }\end{array}$ & - & - & $\begin{array}{l}\text { Colon cancer mouse model } \\
\text { (in vivo) }\end{array}$ & 200 mg/Kg b.w. & Tumor growth suppression & [21] \\
\hline & & $\begin{array}{l}\text { Mastic gum } \\
\text { ethanol extract }\end{array}$ & - & - & Colon carcinoma HCT116 & $0.2-0.6 \% v / v$ & $\begin{array}{c}\text { Dose-dependent inhibition of cell growth } \\
\text { G1 cell cycle arrest } \\
\text { cell death is independent of p53, Bcl-2 and } \\
\text { FADD } \\
\text { Induction of apoptosis } \\
\text { Activation of caspases } 3,8,9 \\
\text { PARP degradation }\end{array}$ & [19] \\
\hline Iridaceae & Crocus sativus L. & $\begin{array}{l}\text { Ethanolic } \\
\text { extract }\end{array}$ & $\begin{array}{c}\text { trans-crocin } 1 \\
(56.4 \%) \\
\text { trans-crocin } 2 \\
(19.2 \%) \\
\text { cis-crocin } 1(6.8 \%)\end{array}$ & $\begin{array}{l}\text { Commercial } \\
\text { (Association } \\
\text { of Crocus } \\
\text { Producers) }\end{array}$ & Rat glioma C6 & $0.5-10 \mathrm{mg} / \mathrm{mL}$ & $\begin{array}{c}\mathrm{EC}_{50}=3 \mathrm{mg} / \mathrm{mL} \\
\text { No apoptosis induction } \\
\text { Colony formation impairment } \\
\text { Calpain-dependent cell death, possibly } \\
\text { autophagy } \\
\text { Synergistic effect with temozolomide at } \\
\text { certain combinations }\end{array}$ & [22] \\
\hline Verbenaceae & Lippia citriodora & Essential oil & $\begin{array}{c}\text { Neral (cis-citral) } \\
(17.2 \%) \\
\text { Geranial } \\
\text { (trans-citral) }(26.4 \%)\end{array}$ & Athens & $\begin{array}{c}\text { Hepatocellular carcinoma } \\
\text { HepG2 } \\
\text { Breast adenocarcinoma MCF-7 } \\
\text { Colon adenocarcinoma Caco2 } \\
\text { Leukemic monocytes THP-1 } \\
\text { Malignant melanoma A375 }\end{array}$ & $0.64-920 \mu \mathrm{g} / \mathrm{mL}$ & $\begin{aligned} \text { HepG2 } \mathrm{EC}_{50} & =74 \pm 2.8 \mu \mathrm{g} / \mathrm{mL} \\
\text { MCF-7 EC } & =89 \pm 1.4 \mu \mathrm{g} / \mathrm{mL} \\
\text { Caco2 EC } 50 & =71 \pm 2.6 \mu \mathrm{g} / \mathrm{mL} \\
\text { THP-1 } \mathrm{EC}_{50} & =111 \pm 3.6 \mu \mathrm{g} / \mathrm{mL} \\
\text { A375 EC } & =9.1 \pm 0.6 \mu \mathrm{g} / \mathrm{mL}\end{aligned}$ & [23] \\
\hline
\end{tabular}


Table 1. Cont

\begin{tabular}{|c|c|c|c|c|c|c|c|c|}
\hline Family & Species & Extract & $\begin{array}{c}\text { Major } \\
\text { Components }\end{array}$ & $\begin{array}{l}\text { Collection } \\
\text { Location }\end{array}$ & Type of Cell & $\begin{array}{c}\text { Dose/ } \\
\text { Concentration }\end{array}$ & Effect & Ref. \\
\hline \multirow[t]{2}{*}{ Rutaceae } & Citrus medica & Essential oil & Limonene (64.35\%) & - & $\begin{array}{c}\text { hepatocellular carcinoma HepG2 } \\
\text { breast adenocarcinoma MCF-7 } \\
\text { colon adenocarcinoma Caco2 } \\
\text { Leukemic monocytes THP-1 } \\
\text { malignant melanoma A375 } \\
\text { immortal keratinocytes HaCat }\end{array}$ & $\begin{array}{c}0.00063-0.9 \\
\mathrm{mg} / \mathrm{mL}\end{array}$ & $\begin{array}{c}\text { HepG2: } \mathrm{EC}_{50}=0.091 \pm 0.012 \mathrm{mg} / \mathrm{mL} \\
\text { MCF-7: } \mathrm{EC}_{50}=0.16 \pm 0.012 \mathrm{mg} / \mathrm{mL} \\
\text { Caco2: } \mathrm{EC}_{50}=0.013 \pm 0.00001 \mathrm{mg} / \mathrm{mL} \\
\mathrm{A} 375: \mathrm{EC}_{50}=0.0057 \pm 0.0019 \mathrm{mg} / \mathrm{mL} \\
\text { HaCat:EC } 50=0.024 \pm 0.0014 \mathrm{mg} / \mathrm{mL}\end{array}$ & [24] \\
\hline & $\begin{array}{l}\text { Fortunella } \\
\text { margarita }\end{array}$ & Essential oil & Limonene $(93.78 \%)$ & Corfu Island & \multirow{4}{*}{$\begin{array}{c}\text { hepatocellular carcinoma HepG2 } \\
\text { breast adenocarcinoma MCF-7 } \\
\text { colon adenocarcinoma Caco2 } \\
\text { leukemic monocytes THP-1 }\end{array}$} & $\begin{array}{c}0.0006-0.86 \\
\mathrm{mg} / \mathrm{mL}\end{array}$ & $\begin{array}{c}\text { HepG2 } \mathrm{EC}_{50}=n . d . \\
\text { MCF-7 } \mathrm{EC}_{50}=n . d . \\
\text { Caco2 } \mathrm{EC}_{50}=0.1 \pm 0.027 \mathrm{mg} / \mathrm{mL} \\
\text { THP-1 } \mathrm{EC}_{50}=0.1 \pm 0.0023 \mathrm{mg} / \mathrm{mL}\end{array}$ & \multirow{4}{*}{25} \\
\hline Apiaceae & $\begin{array}{l}\text { Pimpinella } \\
\text { anisum }\end{array}$ & Essential oil & $\begin{array}{l}\text { trans-Anethole } \\
\quad(88.13 \%)\end{array}$ & - & & $\begin{array}{c}0.00068-0.97 \\
\mathrm{mg} / \mathrm{mL}\end{array}$ & $\begin{array}{c}\text { HepG2 EC } \mathrm{EC}_{50}=0.39 \pm 0.0282 \mathrm{mg} / \mathrm{mL} \\
\text { MCF-7 EC } \mathrm{EC}_{50}=0.3 \pm 0.01 \mathrm{mg} / \mathrm{mL} \\
\text { Caco2 } \mathrm{EC}_{50}=0.25 \pm 0.04 \mathrm{mg} / \mathrm{mL} \\
\text { THP-1 EC } \mathrm{EC}_{50}=0.11 \pm 0.0001 \mathrm{mg} / \mathrm{mL}\end{array}$ & \\
\hline \multirow{5}{*}{ Lamiaceae } & Mentha spicata & Essential oil & Carvone (85.41\%) & - & & $\begin{array}{c}0.00067-0.96 \\
\mathrm{mg} / \mathrm{mL}\end{array}$ & $\begin{array}{c}\text { HepG2 EC } \text { EC }_{50}=0.22 \pm 0.038 \mathrm{mg} / \mathrm{mL} \\
\text { MCF-7 EC } 50=0.284 \pm 0.02 \mathrm{mg} / \mathrm{mL} \\
\text { Caco2 EC } \text { EC }_{50}=0.162 \pm 0.0035 \mathrm{mg} / \mathrm{mL} \\
\text { THP-1 EC } 50=0.71 \pm 0.004 \mathrm{mg} / \mathrm{mL}\end{array}$ & \\
\hline & \multirow{3}{*}{$\begin{array}{l}\text { Ocimum } \\
\text { basilicum }\end{array}$} & Essential oil & $\begin{array}{c}\text { Methyl chavicol } \\
(74.92 \%) \\
\text { Linalool }(18.4)\end{array}$ & - & & $\begin{array}{c}0.00068-0.98 \\
\mathrm{mg} / \mathrm{mL}\end{array}$ & $\begin{array}{l}\text { HepG2 EC } \mathrm{EC}_{50}=0.18 \pm 0.028 \mathrm{mg} / \mathrm{mL} \\
\text { MCF-7 EC } 50=0.17 \pm 0.022 \mathrm{mg} / \mathrm{mL} \\
\text { Caco2 } \mathrm{EC}_{50}=0.071 \pm 0.003 \mathrm{mg} / \mathrm{mL} \\
\text { THP-1 EC } 50=0.67 \pm 0.0021 \mathrm{mg} / \mathrm{mL}\end{array}$ & \\
\hline & & $\begin{array}{l}\text { Ethanolic } \\
\text { extract }\end{array}$ & $\begin{array}{l}\text { Rosmarinic and } \\
\text { caffeic acid }\end{array}$ & Ioannina & \multirow{2}{*}{$\begin{array}{c}\text { cervix adenocarcinoma HeLa } \\
\text { melanoma FemX chronic } \\
\text { myelogenous leukaemia K562 } \\
\text { ovary adenocarcinoma SKOV3 }\end{array}$} & \multirow{2}{*}{$12.5-200 \mu \mathrm{g} / \mathrm{mL}$} & $\begin{array}{c}\text { HeLa: } \mathrm{EC}_{50}=164.61 \pm 2.58 \mu \mathrm{g} / \mathrm{mL} \\
\text { FemX: } \mathrm{EC}_{50}=191.36 \pm 2.42 \mu \mathrm{g} / \mathrm{mL} \\
\text { K562: } \mathrm{EC}_{50}=157.03 \pm 2.25 \mu \mathrm{g} / \mathrm{mL} \\
\text { SKOV3: } \mathrm{EC}_{50}>200 \mu \mathrm{g} / \mathrm{mL}\end{array}$ & \multirow{2}{*}{26} \\
\hline & & Essential oil & $\begin{array}{c}\text { Eugenol, } \\
\text { Isoeugenol, Linalool }\end{array}$ & $\begin{array}{l}\text { Donation from } \\
\text { greenhouse }\end{array}$ & & & $\begin{array}{c}\text { HeLa: } \mathrm{EC}_{50}=86.11 \pm 0.82 \mu \mathrm{g} / \mathrm{mL} \\
\text { FemX: } \mathrm{EC}_{50}=96.72 \pm 0.65 \mu \mathrm{g} / \mathrm{mL} \\
\text { K562: } \mathrm{EC}_{50}=159.78 \pm 1.89 \mu \mathrm{g} / \mathrm{mL} \\
\text { SKOV3: } \mathrm{EC}_{50}>200 \mu \mathrm{g} / \mathrm{mL}\end{array}$ & \\
\hline & $\begin{array}{l}\text { Marrubium } \\
\text { thessalum Boiss. } \\
\text { \& Heldr }\end{array}$ & $\begin{array}{c}\text { Methanolic } \\
\text { extract }\end{array}$ & $\begin{array}{l}\text { Mainly } \\
\text { Phenylethanoid } \\
\text { glycosides and } \\
\text { flavonoids }\end{array}$ & Thessalia & $\begin{array}{c}\text { Breast adenocarcinoma } \\
\text { MCF-7 } \\
\text { cervix adenocarcinoma HeLa } \\
\text { Colon carcinoma HCT116 } \\
\text { Melanoma FM3 } \\
\text { PBMCs }\end{array}$ & $50-750 \mu \mathrm{g} / \mathrm{mL}$ & $\begin{array}{c}\text { MCF-7: } \mathrm{EC}_{50}=417.53 \pm 53.4 \mu \mathrm{g} / \mathrm{mL} \\
\text { HeLa: } \mathrm{EC}_{50}=218.07 \pm 64.1 \mu \mathrm{g} / \mathrm{mL} \\
\text { HCT116:EC } 50=474.07 \pm 23.14 \mu \mathrm{g} / \mathrm{mL} \\
\text { FM3: } \mathrm{EC}_{50}=453.15 \pm 37.91 \mu \mathrm{m} / \mathrm{mL} \\
62.20 \% \text { growth inhibition of PBMCs at } \\
300 \mu \mathrm{g} / \mathrm{mL}\end{array}$ & [27] \\
\hline
\end{tabular}


Table 1. Cont.

\begin{tabular}{|c|c|c|c|c|c|c|c|c|}
\hline Family & Species & Extract & $\begin{array}{c}\text { Major } \\
\text { Components }\end{array}$ & $\begin{array}{l}\text { Collection } \\
\text { Location }\end{array}$ & Type of Cell & $\begin{array}{c}\text { Dose/ } \\
\text { Concentration }\end{array}$ & Effect & Ref. \\
\hline \multirow{5}{*}{ Lamiaceae } & $\begin{array}{l}\text { Satureja } \\
\text { parnassica spp. } \\
\text { parnassica }\end{array}$ & \multirow{2}{*}{ Essential oil } & $\begin{array}{l}\text { Carvacrol }(33.72 \%) \\
\text { Thymol }(17.82 \%) \\
\text {-Cymene }(10.32 \%) \\
\gamma \text {-Terpinene } \\
(15.47 \%)\end{array}$ & $\begin{array}{l}\text { Mt Parnon, } \\
\text { Peloponnese }\end{array}$ & \multirow{2}{*}{$\begin{array}{l}\text { Breast adenocarcinoma } \\
\text { MCF-7 }\end{array}$} & \multirow{2}{*}{$\begin{array}{c}0.00000025-0.25 \% \\
v / v\end{array}$} & $\mathrm{EC}_{50}=0.08 \pm 0.03 \% v / v$ & \multirow{2}{*}{ [28] } \\
\hline & Satureja thymbra & & $\begin{array}{c}\text { Carvacrol }(39.1 \%) \\
\text { Thymol }(12.59 \%) \\
\text { p-Cymene }(8.83 \%) \\
\gamma \text {-Terpinene } \\
(10.61 \%)\end{array}$ & $\begin{array}{l}\text { Mt Immitos, } \\
\text { Attiki }\end{array}$ & & & $\mathrm{EC}_{50}=0.002 \pm 0.00038 \%$ & \\
\hline & $\begin{array}{l}\text { Origanum } \\
\text { vulgare sub. } \\
\text { hirtum }\end{array}$ & Essential oil & Carvacrol (79.58\%) & Euboea & $\begin{array}{c}\text { Larynx carcinoma } \\
\text { Hep-2 } \\
\text { Cervix adenocarcinoma HeLa } \\
\text { African green monkey kidney } \\
\text { Vero } \\
\text { Rabbit skin RSC }\end{array}$ & - & $\begin{array}{l}\text { Complete cell death in all cell lines at } \\
0.0001 \% \mathrm{v} / \mathrm{v} \\
\text { Reduction of Vero viability at } 0.00002 \% v / v \\
\left(\mathrm{EC}_{50}=0.000027 \% \mathrm{v} / \mathrm{v}\right)\end{array}$ & [29] \\
\hline & \multirow[t]{2}{*}{$\begin{array}{c}\text { Origanum Onites } \\
\text { L }\end{array}$} & \multirow[t]{2}{*}{ Essential oil } & \multirow[t]{2}{*}{ Carvacrol (48\%) } & \multirow[t]{2}{*}{$\begin{array}{l}\text { Northern } \\
\text { Greece }\end{array}$} & $\begin{array}{l}\text { Hepatocellular carcinoma } \\
\text { HepG2 } \\
\text { Breast adenocarcinoma MCF-7 } \\
\text { Colon adenocarcinoma HT-29 } \\
\text { Malignant melanoma A375 } \\
\text { Mouse colon carcinoma CT-26 }\end{array}$ & $\begin{array}{c}0.0000589-0.842 \\
\mathrm{mg} / \mathrm{mL}\end{array}$ & $\begin{array}{c}\mathrm{EC}_{50} 48 \mathrm{~h} \\
\text { HT-29: } 58.00 \pm 0.70 \mu \mathrm{g} / \mathrm{mL} \\
\text { CT26: } 71.70 \pm 1.20 \mu \mathrm{g} / \mathrm{mL} \\
\mathrm{EC}_{50} 72 \mathrm{~h} \\
\text { A375: } 8.90 \pm 0.70 \mu \mathrm{g} / \mathrm{mL} \\
\text { MCF-7: } 10.00 \pm 1.70 \mu \mathrm{g} / \mathrm{mL} \\
\text { HepG2: } 23.00 \pm 4.20 \mu \mathrm{g} / \mathrm{mL} \mathrm{HT}-29: \\
0.35 \pm 0.20 \mu \mathrm{g} / \mathrm{mL} \mathrm{CT26:} 1.10 \pm 0.30 \\
\mu \mathrm{g} / \mathrm{mL} \\
\text { Attenuation of colon cancer cell migration } \\
\text { Induction of Apoptosis-Related } \\
\text { Morphological Changes }\end{array}$ & \multirow[t]{2}{*}{30} \\
\hline & & & & & $\begin{array}{l}\text { Colon cancer mouse model } \\
\text { (in vivo) }\end{array}$ & $0.370 \mathrm{~g} / \mathrm{kg} \mathrm{b.w}$ & $52 \%$ lower mean tumor volume & \\
\hline \multirow{4}{*}{ Hypericaceae } & \multirow{4}{*}{$\begin{array}{l}\text { Origanum } \\
\text { dictamnus } \\
\text { (dittany) }\end{array}$} & Essential oil & $\begin{array}{l}\text { Carvacrol }(52.18 \%) \\
\gamma \text {-terpinene }(8.4 \%)\end{array}$ & Crete & $\begin{array}{l}\text { Hepatocellular carcinoma } \\
\text { HepG2 }\end{array}$ & $0.00007-0.1 \% v / v$ & $\mathrm{EC}_{50}=0.0069 \pm 0.00014 \% v / v$ & [31] \\
\hline & & Essential oil & $\begin{array}{c}p \text {-cymene }(32.7 \%) \\
\gamma \text {-terpinene }(12.4 \%)\end{array}$ & Crete & $\begin{array}{c}\text { Colon carcinoma LoVo } \\
\text { Hepatocellular carcinoma } \\
\text { HepG2 }\end{array}$ & $2.5-100 \mu \mathrm{g} / \mathrm{mL}$ & $\begin{array}{c}\text { LoVo: } \mathrm{EC}_{50} 24 \mathrm{~h}=84.76 \pm 1.03 \mu \mathrm{g} / \mathrm{mL} \\
\mathrm{EC}_{50} 48 \mathrm{~h}=72.26 \pm 1.05 \mu \mathrm{g} / \mathrm{mL} \\
\text { HepG2: Reduction of cell viability }\end{array}$ & [32] \\
\hline & & $\begin{array}{c}\text { Dichloro- } \\
\text { methane residue }\end{array}$ & Ursolic acid & \multirow{2}{*}{ Crete } & \multirow{2}{*}{$\begin{array}{l}\text { Mouse leukemia P-388 } \\
\text { Non-small cell lung carcinoma } \\
\text { NSCLC-N6 }\end{array}$} & \multirow{2}{*}{-} & $\begin{array}{c}\text { P-388: } \mathrm{EC}_{50}=8 \mu \mathrm{g} / \mathrm{mL} \\
\text { NSCLC-N6: } \mathrm{EC}_{50}=14 \mu \mathrm{g} / \mathrm{mL}\end{array}$ & \multirow{2}{*}{33} \\
\hline & & $\begin{array}{l}\text { Ethanolic } \\
\text { extract }\end{array}$ & - & & & & Almost inactive & \\
\hline
\end{tabular}


Table 1. Cont

\begin{tabular}{|c|c|c|c|c|c|c|c|c|}
\hline Family & Species & Extract & $\begin{array}{c}\text { Major } \\
\text { Components }\end{array}$ & $\begin{array}{l}\text { Collection } \\
\text { Location }\end{array}$ & Type of Cell & $\begin{array}{c}\text { Dose/ } \\
\text { Concentration }\end{array}$ & Effect & Ref. \\
\hline \multirow{12}{*}{ Hypericaceae } & $\begin{array}{l}\text { Origanum } \\
\text { dictamnus } \\
\text { (dittany) }\end{array}$ & \multirow{6}{*}{ Infusion } & 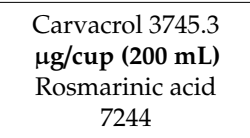 & \multirow{5}{*}{ Crete } & \multirow{6}{*}{$\begin{array}{c}\text { Colon carcinoma HT-29 } \\
\text { Prostate adenocarcinoma PC-3 }\end{array}$} & \multirow{6}{*}{$0.2,0.6,1 \mu \mathrm{g} / \mu \mathrm{L}$} & \multirow{6}{*}{$\begin{array}{c}\text { PC3 antiproliferative activity: Origanum } \\
\text { dictamnus }>\text { marjoram }>\text { sage }>\text { rosemary }>\text { St } \\
\text { John's wort }>\text { thyme } \\
\text { HT-29 antiproliferative activity: Origanum } \\
\text { dictamnus }>\text { rosemary }> \\
\text { thyme }>\text { sage }>\text { marjoram }>\text { St John's wort } \\
\text { IL-8 decrease in HT-29: sage }>\text { Origanum } \\
\text { dictamnus }>\text { thyme }>\text { marjoram }>\text { St John's } \\
\text { wort }>\text { rosemary } \\
\text { IL-8 decrease in PC-3: Thyme }>\text { sage }> \\
\text { Origanum dictamnus }>\text { marjoram }> \\
\text { rosemary }>\text { St John's wort } \\
\text { Reduced levels of the p65 NF-kB subunit } \\
\text { by St John's Wort in HT29 } \\
\text { and thyme in PC3 }\end{array}$} & \multirow{6}{*}{34} \\
\hline & $\begin{array}{l}\text { Rosmarinus } \\
\text { officinalis } \\
\text { (rosemary) }\end{array}$ & & $\begin{array}{l}\text { Rosmarinic acid } 669 \\
\text { Carvacrol } 362.3\end{array}$ & & & & & \\
\hline & $\begin{array}{l}\text { Thymus } \\
\text { Vulgaris } \\
\text { (thyme) }\end{array}$ & & $\begin{array}{l}\text { Carvacrol 182,138 } \\
\text { Thymol 80,655 }\end{array}$ & & & & & \\
\hline & $\begin{array}{l}\text { Origanum } \\
\text { majorana } \\
\text { (marjoram) }\end{array}$ & & $\begin{array}{c}\text { Rosmarinic acid } \\
9674.4 \\
\text { Carvacrol } 2796\end{array}$ & & & & & \\
\hline & $\begin{array}{c}\text { Salvia } \\
\text { officinalis (sage) }\end{array}$ & & $\begin{array}{l}\text { Rosmarinic acid } \\
8082.7 \\
\text { Carvacrol } 3745\end{array}$ & & & & & \\
\hline & \multirow{7}{*}{$\begin{array}{l}\text { Hypericum } \\
\text { perforatum } \\
\text { (St John's Wort) }\end{array}$} & & $\begin{array}{l}\text { Epicatechin } 29,275.4 \\
\text { Catechin } 3448.2 \\
\text { Quercetin } 3134\end{array}$ & $\begin{array}{c}\text { Central } \\
\text { Macedonia }\end{array}$ & & & & \\
\hline & & $\begin{array}{l}\text { Methanolic } \\
\text { extract }\end{array}$ & $\begin{array}{l}\text { Hypericin } \\
\text { hyperforin }\end{array}$ & $\begin{array}{l}\text { Wild collected } \\
\text { 38/15, 41/15: } \\
\text { North-West } \\
\text { Macedonia } \\
\text { 43/15: } \\
\text { North-Central } \\
\text { Macedonia }\end{array}$ & $\begin{array}{l}\text { Colon adenocarcinoma } \\
\text { Caco2 }\end{array}$ & $0.01-100 \mu \mathrm{g} / \mathrm{mL}$ & $\begin{array}{l}\text { 38/15 \& 41/15: Did not affect cell viability } \\
\text { 43/15: Reduced viability to } 82.04 \% \text { only at } \\
\text { the highest concentration }\end{array}$ & [35] \\
\hline & & & & $\begin{array}{l}\text { Cultivated } \\
\text { NAT, D-4: } \\
\text { North Greece }\end{array}$ & & & $\begin{array}{c}\text { NAT: Reduced viability to } 41.14 \% \text { only at } \\
\text { the highest concentration } \\
\text { D-4: Did not affect cell viability }\end{array}$ & \\
\hline & & $\begin{array}{c}\text { Aqueous } \\
\text { solution (AS) }\end{array}$ & - & \multirow{4}{*}{ Ioannina } & \multirow{4}{*}{$\begin{array}{c}\text { Urinary bladder carcinoma T24 } \\
\text { Rat urinary bladder carcinoma } \\
\text { NBT-II }\end{array}$} & \multirow{4}{*}{$\begin{array}{c}\text { AS and MS: } \\
0.63-20 \mu L / m L \\
\text { ME: } 13-40 \\
\mu \mathrm{g} / \mathrm{mL} \\
\text { PEE: } 2-12 \\
\mu \mathrm{g} / \mathrm{mL}\end{array}$} & $\begin{array}{l}\mathrm{T}_{2} 4: \mathrm{AS} \mathrm{EC}_{50}=4.7 \mu \mathrm{L} / \mathrm{mL} \\
\mathrm{MS} \mathrm{EC}_{50}=1.1 \mu \mathrm{L} / \mathrm{mL}\end{array}$ & \multirow{4}{*}{36} \\
\hline & & $\begin{array}{l}\text { Methanolic } \\
\text { solution (MS) }\end{array}$ & - & & & & $\begin{array}{l}\mathrm{ME} \mathrm{EC}_{50}=18 \mu \mathrm{g} / \mathrm{mL} \\
\mathrm{PEE} \mathrm{EC}_{50}=5 \mu \mathrm{g} / \mathrm{mL}\end{array}$ & \\
\hline & & $\begin{array}{l}\text { Methanolic } \\
\text { extract (ME) }\end{array}$ & Hyperforin $(7.62 \%)$ & & & & $\begin{array}{c}\text { NBT-II: } \mathrm{ME} \mathrm{EC}_{50}=13 \mu \mathrm{g} / \mathrm{mL} \\
\text { PEE EC } 50=7 \mu \mathrm{g} / \mathrm{mL}\end{array}$ & \\
\hline & & $\begin{array}{l}\text { Petroleum ether } \\
\text { extract (PEE) }\end{array}$ & Hyperforin (18.9\%) & & & & and NBT-II cells by PEE extract & \\
\hline
\end{tabular}


Table 1. Cont

\begin{tabular}{|c|c|c|c|c|c|c|c|c|}
\hline Family & Species & Extract & $\begin{array}{c}\text { Major } \\
\text { Components }\end{array}$ & $\begin{array}{l}\text { Collection } \\
\text { Location }\end{array}$ & Type of Cell & $\begin{array}{c}\text { Dose/ } \\
\text { Concentration }\end{array}$ & Effect & Ref. \\
\hline \multirow{5}{*}{ Hypericaceae } & $\begin{array}{c}\text { Hypericum } \\
\text { perforatum } \\
\text { (St John's Wort) }\end{array}$ & & - & $\begin{array}{l}\text { Monodendrl, } \\
\text { Epirus }\end{array}$ & \multirow{5}{*}{$\begin{array}{c}\text { Colon carcinoma Caco2 } \\
\text { Hepatocellular carcinoma } \\
\text { HepG2 }\end{array}$} & \multirow{5}{*}{$10-100 \mathrm{mg} / \mathrm{mL}$} & \multirow{5}{*}{$\begin{array}{c}\mathrm{EC}_{50} \text { of all extracts against all cell cancer } \\
\text { lines }>100 \mathrm{mg} / \mathrm{mL} \text {, apart from: } \\
\text { H. empetrifolium Wild Parnitha: } \\
\text { Caco2 } \mathrm{EC}_{50}=51.3 \mathrm{mg} / \mathrm{mL} \\
\text { HepGE } \mathrm{EC}_{50}=43.7 \mathrm{mg} / \mathrm{mL} \\
\text { H. empetrifolium } \text { Wild Hymettus: } \\
\text { Caco2 } \mathrm{EC}_{50}=54.2 \mathrm{mg} / \mathrm{mL} \\
\text { HepG2 } \mathrm{EC}_{50}=45.8 \mathrm{mg} / \mathrm{mL} \\
\text { H. empetrifolium } \text { Wild Parnon: } \\
\text { Caco2 } \mathrm{EC}_{50}=29 \mathrm{mg} / \mathrm{mL} \\
\text { HepG2 } \mathrm{EC}_{50}=25.1 \mathrm{mg} / \mathrm{mL}\end{array}$} & \multirow{5}{*}{37} \\
\hline & $\begin{array}{l}\text { Hypericum } \\
\text { empetrifolium } \\
\text { Wild }\end{array}$ & Methanolic & - & $\begin{array}{c}\text { Mt. Parnitha, } \\
\text { Attiki } \\
\text { Mt.Hymettos, } \\
\text { Attiki } \\
\text { Parnon, } \\
\text { Arkadia }\end{array}$ & & & & \\
\hline & $\begin{array}{l}\text { Hypericum } \\
\text { rumeliacum } \\
\text { Boiss. } \\
\end{array}$ & & - & $\begin{array}{l}\text { Mt. Parnassos, } \\
\text { Viotia }\end{array}$ & & & & \\
\hline & $\begin{array}{l}\text { Hypericum } \\
\text { perfoliatum } \mathrm{L} .\end{array}$ & & - & $\begin{array}{l}\text { Korinthos } \\
\text { Preveza }\end{array}$ & & & & \\
\hline & $\begin{array}{l}\text { Hypericum } \\
\text { triquetrifolium } \\
\text { Turra }\end{array}$ & & - & $\begin{array}{l}\text { Rafina, Attiki } \\
\text { Lakonia } \\
\text { Crete }\end{array}$ & & & & \\
\hline \multirow{4}{*}{ Lamiaceae } & $\begin{array}{l}\text { Teucrium } \\
\text { brevifolium }\end{array}$ & Essential oil & $\begin{array}{l}\text { Spathulenol }(9 \%) \\
\delta \text {-cadinene }(4.2 \%)\end{array}$ & $\begin{array}{l}\text { Karpathos } \\
\text { Island }\end{array}$ & \multirow{4}{*}{$\begin{array}{c}\text { Lung carcinoma COR-L23 } \\
\text { Colorectal adenocarcinoma } \\
\text { Caco2 } \\
\text { Amelanotic melanoma C32 }\end{array}$} & \multirow{4}{*}{$5-200 \mu \mathrm{g} / \mathrm{mL}$} & $\begin{array}{c}\text { COR-L23: } \mathrm{EC}_{50}=80.7 \pm 2.1 \mu \mathrm{g} / \mathrm{mL} \\
\text { Caco2: } \mathrm{EC}_{50}=164 \pm 2.1 \mu \mathrm{g} / \mathrm{mL} \\
\text { C32: } \mathrm{EC}_{50}>200 \mu \mathrm{g} / \mathrm{mL}\end{array}$ & \multirow{4}{*}{ [38] } \\
\hline & Teucrium flavum & Essential oil & $\begin{array}{c}\text { caryophyllene } \\
(12.2 \%) \\
\text { 4-vinyl guaiacol } \\
(9.7 \%) \\
\text { caryophyllene oxide } \\
(7.9 \%)\end{array}$ & $\begin{array}{l}\text { Pelion } \\
\text { mountain }\end{array}$ & & & $\begin{array}{c}\text { COR-L23: } \mathrm{EC}_{50}=104 \pm 2.1 \mu \mathrm{g} / \mathrm{mL} \\
\text { Caco2: } \mathrm{EC}_{50}>200 \mu \mathrm{g} / \mathrm{mL} \\
\text { C32: } \mathrm{EC}_{50}>200 \mu \mathrm{g} / \mathrm{mL}\end{array}$ & \\
\hline & $\begin{array}{c}\text { Teucrium } \\
\text { montbretii ssp. } \\
\text { heliotropiifolim }\end{array}$ & Essential oil & $\begin{array}{c}\text { Carvacrol }(13.9 \%) \\
\text { caryophyllene oxide } \\
(12.7 \%)\end{array}$ & $\begin{array}{l}\text { Karpathos } \\
\text { Island }\end{array}$ & & & $\begin{array}{c}\text { COR-L23: } \mathrm{EC}_{50}=143 \pm 2.1 \mu \mathrm{g} / \mathrm{mL} \\
\text { Caco2: } \mathrm{EC}_{50}=92.2 \pm 2.1 \mu \mathrm{g} / \mathrm{mL} \\
\text { C32: } \mathrm{EC}_{50}=135 \pm 2.1 \mu \mathrm{g} / \mathrm{mL}\end{array}$ & \\
\hline & $\begin{array}{l}\text { Teucrium polium } \\
\text { ssp. capitatum }\end{array}$ & Essential oil & $\begin{array}{c}\text { Carvacrol }(10.1 \%), \\
\text { caryophyllene } \\
(9.8 \%) \\
\text { torreyol }(7.6 \%)\end{array}$ & Crete & & & $\begin{array}{c}\text { COR-L23: } \mathrm{EC}_{50}=104 \pm 2.1 \mu \mathrm{g} / \mathrm{mL} \\
\text { Caco2: } \mathrm{EC}_{50}=52.7 \pm 2.1 \mu \mathrm{g} / \mathrm{mL} \\
\text { C32: } \mathrm{EC}_{50}=91.2 \pm 2.1 \mu \mathrm{g} / \mathrm{mL}\end{array}$ & \\
\hline
\end{tabular}


Table 1. Cont.

\begin{tabular}{|c|c|c|c|c|c|c|c|c|}
\hline Family & Species & Extract & $\begin{array}{c}\text { Major } \\
\text { Components }\end{array}$ & $\begin{array}{l}\text { Collection } \\
\text { Location }\end{array}$ & Type of Cell & $\begin{array}{c}\text { Dose/ } \\
\text { Concentration }\end{array}$ & Effect & Ref. \\
\hline Asteraceae & $\begin{array}{l}\text { Matriacaria } \\
\text { chamomilla } \\
\text { (chamomile) }\end{array}$ & \multirow{6}{*}{ infusion } & $\begin{array}{c}\text { Carvacrol } 9321.5 \\
\mu \mathrm{g} / \mathrm{cup}(200 \mathrm{~mL}) \\
\text { Chlorogenic acid } \\
4800.34 \\
\end{array}$ & \multirow{6}{*}{ Crete } & \multirow{6}{*}{$\begin{array}{c}\text { Colon carcinoma } \\
\text { HT-29 } \\
\text { Prostate adenocarcinoma PC-3 }\end{array}$} & \multirow{6}{*}{$0.2,0.6,1 \mu \mathrm{g} / \mu \mathrm{L}$} & $\begin{array}{l}\text { HT-29: Pink savory most effective, } \\
\text { chamomile least cytotoxic } \\
\text { PC-3: Pink savory most effective, }\end{array}$ & \multirow{6}{*}{39} \\
\hline \multirow{12}{*}{ Lamiaceae } & $\begin{array}{l}\text { Origanum } \\
\text { microphyllum }\end{array}$ & & Carvacrol 23,274 & & & & $\begin{array}{c}\text { chamomile and mountain tea least } \\
\text { cytotoxic }\end{array}$ & \\
\hline & $\begin{array}{l}\text { Sideritis syriaca } \\
\text { (mountain tea) }\end{array}$ & & $\begin{array}{l}\text { Carvacrol } 1220 \\
\text { Chlorogenic acid } \\
828.49 \\
\end{array}$ & & & & $\begin{array}{c}\text { IL-8 decrease in HT-29: mountain tea }> \\
\text { pennyroyal }>\text { chamomile }>\text { Origanum } \\
\text { microphyllum }>\text { pink savory }>\text { Origanum } \\
\text { vulgare }\end{array}$ & \\
\hline & $\begin{array}{l}\text { Origanum } \\
\text { vulgare }\end{array}$ & & $\begin{array}{l}\text { Carvacrol } 177,855 \\
\text { Thymol } 2545\end{array}$ & & & & $\begin{array}{l}\text { IL-8 decrease in PC-3: Origanum } \\
\text { microphyllum }>\text { pennyroyal > pink savory }\end{array}$ & \\
\hline & $\begin{array}{l}\text { Satureja thymbra } \\
\text { (pink savory) }\end{array}$ & & $\begin{array}{l}\text { Carvacrol } 87,814 \\
\text { Thymol } 34,382\end{array}$ & & & & $\begin{array}{c}>\text { Origanum vulgare }>\text { chamomile }> \\
\text { mountain tea }\end{array}$ & \\
\hline & $\begin{array}{l}\text { Mentha pulegium } \\
\text { (pennyroyal) }\end{array}$ & & $\begin{array}{c}\text { Carvacrol } 3755 \\
\text { Thymol } 1727\end{array}$ & & & & $\begin{array}{l}\text { chamomile in HT-29 cells } \\
\text { ch }\end{array}$ & \\
\hline & & \multirow{7}{*}{$\begin{array}{l}\text { Methanolic } \\
\text { extract }\end{array}$} & - & Lesvos Island & \multirow{7}{*}{$\begin{array}{c}\text { Breast adenocarcinoma MCF-7 } \\
\text { Colon carcinoma Caco2 } \\
\text { Hepatocellular carcinoma } \\
\text { HepG2 } \\
\text { Normal mouse adipose areolar } \\
\text { cells }\end{array}$} & \multirow{7}{*}{$10-100 \mu \mathrm{g} / \mathrm{mL}$} & \multirow{7}{*}{$\begin{array}{c}\mathrm{EC}_{50} \text { of all extracts against all cell } \\
\text { cancer lines }>75 \mu \mathrm{g} / \mathrm{mL} \text {, apart from: } \\
\text { Clinopodium vulgare: } \\
\text { MCF-7 } \mathrm{EC}_{50}=60.4 \mu \mathrm{\mu g} / \mathrm{mL} \\
\text { Rosmarinus officinalis: } \\
\mathrm{MCF}-7 \mathrm{EC}_{50}=42.6 \mu \mathrm{gg} / \mathrm{mL} \\
\text { Thymus parnassicus Halácsy: } \\
\text { Caco2 } \mathrm{EC}_{50}=44.6 \mu \mathrm{g} / \mathrm{mL} \\
\mathrm{HepG} 2 \mathrm{EC}_{50}=50.3 \mu \mathrm{\mu g} / \mathrm{mL} \\
\text { MCF-7 EC } 50=54.7 \mu \mathrm{g} / \mathrm{mL} \\
\text { Rosmarinus officinalis was the most } \\
\text { cytotoxic against a normal mouse adipose } \\
\text { arelar cell lines at } 100 \mu \mathrm{g} / \mathrm{mL}\end{array}$} & \multirow{7}{*}{40} \\
\hline & $\begin{array}{l}\text { Micromeria } \\
\text { juliana (L.) } \\
\text { Bentham ex } \\
\text { Reinchenb. }\end{array}$ & & - & $\begin{array}{l}\text { Mt Parnassos, } \\
\text { Viotia }\end{array}$ & & & & \\
\hline & $\begin{array}{l}\text { Nepeta argolica } \\
\text { Bory et Chaub. } \\
\text { subsp. argolica }\end{array}$ & & - & $\begin{array}{l}\text { Mt. Parnitha, } \\
\text { Attiki }\end{array}$ & & & & \\
\hline & $\begin{array}{l}\text { Phlomis pungens } \\
\text { Willd. }\end{array}$ & & - & $\begin{array}{c}\text { Mt Parnassos, } \\
\text { Viotia } \\
\end{array}$ & & & & \\
\hline & $\begin{array}{l}\text { Rosmarinus } \\
\text { officinalis L. }\end{array}$ & & - & Zante Island & & & & \\
\hline & Satureja graeca $\mathrm{L}$ & & - & $\begin{array}{l}\text { Mt. Penteli, } \\
\text { Attiki }\end{array}$ & & & & \\
\hline & $\begin{array}{l}\text { Scutellaria } \\
\text { rupestris Boiss. } \\
\text { \& Heldr }\end{array}$ & & - & $\begin{array}{l}\text { Mt. Parnitha, } \\
\text { Attiki }\end{array}$ & & & & \\
\hline
\end{tabular}


Table 1. Cont.

\begin{tabular}{|c|c|c|c|c|c|c|c|c|}
\hline Family & Species & Extract & $\begin{array}{c}\text { Major } \\
\text { Components }\end{array}$ & $\begin{array}{c}\text { Collection } \\
\text { Location }\end{array}$ & Type of Cell & $\begin{array}{c}\text { Dose/ } \\
\text { Concentration }\end{array}$ & Effect & Ref. \\
\hline \multirow{12}{*}{ Lamiaceae } & $\begin{array}{l}\text { Sideritis sipylea } \\
\text { Boiss }\end{array}$ & \multirow{12}{*}{$\begin{array}{c}\text { Methanolic } \\
\text { extract }\end{array}$} & - & Lesvos Island & \multirow{12}{*}{$\begin{array}{c}\text { Breast adenocarcinoma MCF-7 } \\
\text { Colon carcinoma Caco2 } \\
\text { Hepatocellular carcinoma } \\
\text { HepG2 } \\
\text { Normal mouse adipose areolar } \\
\text { cells }\end{array}$} & \multirow{12}{*}{$10-100 \mu \mathrm{g} / \mathrm{mL}$} & \multirow{12}{*}{$\begin{array}{c}\mathrm{EC}_{50} \text { of all extracts against all cell } \\
\text { cancer lines }>75 \mu \mathrm{\mu g} / \mathrm{mL} \text {, apart from: } \\
\text { Clinopodium vulgare: } \\
\text { MCF-7 } \mathrm{EC}_{50}=60.4 \mu \mathrm{g} / \mathrm{mL} \\
\text { Rosmarinus officinalis: } \\
\mathrm{MCF}-7 \mathrm{EC}_{50}=42.6 \mu \mathrm{g} / \mathrm{mL} \\
\text { Thymus parnassicus Halácsy: } \\
\text { Caco2 } \mathrm{EC}_{50}=44.6 \mu \mathrm{g} / \mathrm{mL} \\
\text { HepG2 } \mathrm{EC}_{50}=50.3 \mu \mathrm{g} / \mathrm{mL} \\
\text { MCF-7 } \mathrm{EC}_{50}=54.7 \mu \mathrm{g} / \mathrm{mL} \\
\\
\text { Rosmarinus officinalis was the most } \\
\text { cytotoxic against a normal mouse adipose } \\
\text { arelar cell lines at } 100 \mu \mathrm{g} / \mathrm{mL}\end{array}$} & \multirow{12}{*}{ [40] } \\
\hline & Stachys spruneri & & - & $\begin{array}{l}\text { Mt. Parnitha, } \\
\text { Attiki }\end{array}$ & & & & \\
\hline & & & - & $\begin{array}{l}\text { Mt. Pateras, } \\
\text { Attiki }\end{array}$ & & & & \\
\hline & $\begin{array}{c}\text { Teucrium } \\
\text { divaricatum } \\
\text { Heldr. ssp. } \\
\text { divaricatum }\end{array}$ & & - & $\begin{array}{l}\text { Mt.- Pateras, } \\
\text { Attiki }\end{array}$ & & & & \\
\hline & $\begin{array}{l}\text { Teucrium polium } \\
\text { L. }\end{array}$ & & - & $\begin{array}{l}\text { Mt.Hymettus, } \\
\text { Attiki }\end{array}$ & & & & \\
\hline & $\begin{array}{l}\text { Thymus atticus } \\
\text { Celak. }\end{array}$ & & - & $\begin{array}{l}\text { Mt. Parnitha, } \\
\text { Attiki }\end{array}$ & & & & \\
\hline & $\begin{array}{c}\text { Thymus } \\
\text { longicaulis C. } \\
\text { Presl }\end{array}$ & & - & Trikala & & & & \\
\hline & $\begin{array}{c}\text { Thymus } \\
\text { parnassicus } \\
\text { Halacsy }\end{array}$ & & - & $\begin{array}{l}\text { Mt. Kitheron, } \\
\text { Attiki }\end{array}$ & & & & \\
\hline & $\begin{array}{c}\text { Thymus samius } \\
\text { Ronniger \& } \\
\text { Rech }\end{array}$ & & - & Samos Island & & & & \\
\hline & $\begin{array}{c}\text { Thymus } \\
\text { teucrioides Boiss. } \\
\text { \& Spruner }\end{array}$ & & - & $\begin{array}{l}\text { Domokos, } \\
\text { Fthiotida }\end{array}$ & & & & \\
\hline & $\begin{array}{l}\text { Clinopodium } \\
\text { vulgare } \mathrm{L}\end{array}$ & & - & $\begin{array}{l}\text { Mt. Parnitha, } \\
\text { Attiki }\end{array}$ & & & & \\
\hline & $\begin{array}{l}\text { Lavandula } \\
\text { stoechas L. }\end{array}$ & & - & Lesvos Island & & & & \\
\hline
\end{tabular}


Citrus medica (citron) is an evergreen shrub or small tree that produces citron, probably the only citrus fruit known in Europe in ancient times that has been extensively used for its medicinal properties as reviewed in detail in [41]. It was found that the oil of citron is cytotoxic against human cancer cell lines in vitro, especially against the colon carcinoma $\mathrm{Caco} 2$, while it affected a non-tumorigenic human cell line to a lesser extent. Its cytotoxicity was higher compared to its major component, limonene [24].

Lippia citriodora (or Aloysia citriodora, Aloysia triphylla), commonly known as lemon verbena, belongs to the Verbenaceae family. It was cultivated in South and Central America and was brought to Europe in the 17th century [42]. Its leaves are mainly used for the preparation of infusions and decoctions, usually consumed for the relief of gastroinstestinal problems, but they have also been used as anti-spasmodic, diuretic, or sedatives [43]. There are published data on the antiproliferative activity of the essential oil from plants of different origin (Morocco and Colombia), but only one study on the bioactivities of the Greek oil exists. Lemon verbena oil demonstrated high antiproliferative activity against a panel of human cancer cell lines (A375 > Caco2 > HepG2 > MCF-7 > THP-1), which was lower than its major component, citral, possibly due to the lower DNA-damaging effect it was shown to possess [23].

Satureja parnassica spp. parnassica is an aromatic plant endemic to Central and Southern Greece. Although literature is sparse regarding its activity, existing studies reveal a potent antimicrobial and insecticidal profile of its essential oil [44,45]. Satureja thymbra (common names: Thyme-leaved savory, pink savory, thrubi) is an aromatic plant endemic to the Mediterranean region and is the most common specimen of the Satureja genus. It is regarded as oil-rich and its essential oil has been tested against several models and was shown to possess potent antioxidant, antifungal, antibacterial, antiviral, and insecticidal properties [44-49]. In a study published in 2016, the antiproliferative activity of the essential oils of S. thymbra and S. parnassica collected after their flowering season (August and September, respectively) and their major components were investigated [28]. It was shown that the oil of S. thymbra was more cytotoxic against MCF- 7 cells, possibly due to its higher content in carvacrol, a phenol with significant bioactivities [50].

Origanum vulgare spp. hirtum (also known as Greek oregano) is considered the best for culinary purposes. It is the most common $O$. vulgare subspecies in the Greek area and has shown great variation in its chemical composition depending on the cultivation area [51]. Its essential oil was studied against two normal cell lines of monkey and rabbit origin (Vero, RSC, respectively) and two human cancer cell lines (Hep-2, HeLa) without exhibiting any cancer-specific cytototoxicity. In fact, the oil was found to be more cytotoxic against Vero cells compared to the other cell lines [29].

Another member of the Origanum genus, Origanum Onites L., is commercially known as Turkish oregano and can be mainly found in Turkey, but also in Greece and a small part of Sicily. Different extracts of the plant are used for the relief of common health problems and this has led to the investigation of their pharmacological properties, as well (reviewed in [52]). In a recent study, the essential oil of O. Onites isolated from plants collected in Northern Greece has shown dose-dependent antiproliferative activity in vitro, especially against the colon cancer cell line HT-29 (followed by A375, MCF-7 and HepG2 carcinomas). Treatment with the oil caused time-dependent cytotoxicity against HT-29 and CT26 cells (murine colon cancer cell line), attenuation of their migration, and apoptosis-like features, while oral administration for 13 days significantly inhibited the growth of CT26 tumors in mice [30].

Origanum dictamnus (dittany of Crete), is a perennial plant endemic to the island of Crete that grows at different altitudes. The essential oil of the plant demonstrated time-dependent cytotoxicity against the LoVo colon cancer cell line, while it reduced the viability of HepG2 cells [31,32]. A dichloromethane residue was almost two-fold more cytotoxic against the leukemic cells P-388 compared to the lung carcinoma NSCLC-N6; however, the ethanol extract appeared to be almost inactive against these cell lines. The difference in their activity could be attributed to the presence of ursolic acid in the dichloromethane residue, which was shown to be more cytotoxic than the residue against the cancer cell lines [33]. Finally, the herbal infusion of the aerial parts of the plant was the most cytotoxic against HT-29 and PC-3 cells compared to infusions from other Greek plants [34]. 
In the same study, Rosmarinus officinalis (rosemary), Thymus vulgaris (thyme), Origanum majorana (marjoram), Salvia officinalis (sage), and Hypericum perforatum (St John's Wort) were also studied. The infusions of marjoram and St John's wort were the least cytotoxic against HT-29 cells, while PC-3 were the least sensitive against thyme. St John's Wort in HT29 and thyme in PC3 cells caused reduction of the levels of the p65 NF-kB subunit and all infusions decreased the levels of the pro-inflammatory interleukin 8 , in an order depending on the cell line. The authors could not make a correlation between the antiproliferative profile of the extracts and their composition.

A similar study was conducted a year before, in 2013, where the antiproliferative activity of herbal infusions from leaves and flowers of the plants Origanum vulgare, Origanum microphyllum, Satureja thymbra (pink savory), Sideritis syriaca (mountain tea), Mentha pulegium (pennyroyal), and Matricaria chamomilla (chamomile) was tested [39]. The authors showed that pink savory was the most cytotoxic against HT-29 and PC-3 cells, while chamomile infusion and chamomile together with mountain tea were the least effective against HT-29 and PC-3 cells, respectively. However, the infusion of chamomile was the only one that caused statistically significant reduction of the p65 NF-kB subunit in HT-29 cells. In addition, all infusions were able to decrease the levels of interleukin-8 in the following order: HT-29: mountain tea $>$ pennyroyal $>$ chamomile $>$ Origanum microphyllum $>$ pink savory $>$ Origanum vulgare, PC-3: Origanum microphyllum $>$ pennyroyal $>$ pink savory $>$ Origanum vulgare $>$ chamomile $>$ mountain tea.

St. John's Wort is mainly known for its use against depression and anxiety; however, there is emerging evidence for its potential against cancer, too [53]. The aqueous and methanolic solution (AS and MS) as well as the methanolic and petroleum ether extracts (ME and PEE) of St John's Wort from Epirus were tested against the urinary bladder carcinoma T24 and the rat urinary bladder carcinoma NBT-II. The MS was more potent than the AS against T24 cells and the same applied for the PEE compared to the ME. The PEE was also more cytotoxic than the ME against the NBT-II cell line, which is attributed to yet unidentifiable components of the herb. PEE was also shown to induce apoptosis in both cell lines using the TUNEL assay [36]. A methanolic extract of the plant together with methanolic extracts from four other species of the genus Hypericum (H. empetrifolium, perfoliatum, rumeliacum, triquetrifolium) showed diverse antioxidant activity and cytotoxicity against Caco 2 and HepG2 cells, with the extracts of H. empetrifolium Wild from three different locations being the most cytotoxic; however, the concentrations used were very high [37]. Methanolic extracts from aerial parts of different St John's wort's chemotypes from different locations (cultivated and wild) were tested against Caco2 cells [35]. The highest activity was presented by one of the cultivated chemotypes, followed by one of the wild populations, while the other extracts did not affect cell viability at all. They also included a commercial sample in their analysis, but it was not of Greek origin. The authors found positive correlation between the antiproliferative activity and the content in rutin and hyperforin, two main components of Hypericum species. Differences in their content were attributed to different environmental conditions at the growing sites of the plants.

The methanolic extracts of pennyroyal and rosemary and other 16 plants mainly from Attiki region and Lesvos island (Clinopodium vulgare L., Lavandula stoechas L., Micromeria juliana L. Bentham ex Reinchenb., Nepeta argolica Bory et Chaub. subsp. argolica, Phlomis pungens Wild., Satureja graeca L., Scutellaria rupestris Boiss. \& Heldr., Sideritis sipylea Boiss., Stachys spruneri Boiss., Teucrium divaricatum Heldr. subsp. divaricatum, Teucrium polium L., Thymus atticus Čelak., Thymus longicaulis C. Presl, Thymus parnassicus Halacsy, Thymus samius Ronniger \& Rech., Thymus teucrioides Boiss. \& Spruner) have been investigated against three human cancer cells lines (MCF-7, Caco2, HepG2) and normal mouse adipose areolar cells [40]. Rosemary was the most potent against MCF-7 cells, while Thymus parnassicus Halácsy against Caco2 and HepG2; however, rosemary extract was also the most cytotoxic towards the normal mouse cell line used. In the same study, the extracts were also tested for their toxicity against brine shrimps and pennyroyal was found to be the most cytotoxic $\left(\mathrm{LC}_{50}=347.3 \mu \mathrm{g} / \mathrm{mL}\right)$.

The genus Teucrium can be found worldwide but mostly in the Mediterranean region. Menichini and her colleagues in 2009 studied the antiproliferative potential of four Teucrium species from 
Greece [38]. More specifically, the essential oil from the aerial parts of T. brevifolium, T. flavum, T. montbretii ssp. Heliotropiifolium, and T. polium ssp. capitatum were isolated and studied against lung carcinoma COR-L23, colorectal adenocarcinoma Caco2, and amelanotic melanoma C32. They observed that T. brevifolium oil was the most potent againstCOR-L23 cells, while Teucrium polium ssp. capitatum was the most potent against $\mathrm{Caco} 2$ and $\mathrm{C} 32$ cells. The authors attributed the diverse activity to the different classes of compounds present in the oils (different classes of sesquiterpenes). All oils also exhibited anti-inflammatory activity, being able to inhibit LPS-induced NO production, with T. brevifolium possessing the highest capacity.

Crocus sativus L. is an aromatic flowering plant, which produces saffron spice, the most expensive spice in the world, known as "red gold" [54]. The herb has been widely used by ancient Indian, Arabic, and Chinese civilizations as medicine, but is also studied nowadays for its therapeutic potential against several pathological conditions including depression, diabetes, and cancer [55]. In a recent study, Giakoumettis and his colleagues investigated the antiproliferative effect of an ethanolic saffron extract against rat glioma cells $\mathrm{C} 6$ alone or in combination with the chemotherapeutic drug temozolomide (TMZ). They showed that the saffron extract is cytotoxic against the cell line after $48 \mathrm{~h}$ of treatment and in some combinations, it enhances the cytotoxicity of the drug, too. In addition, they demonstrated that the extract does not induce apoptosis, but calpain-dependent death, possibly through the activation of autophagy and also impairs the colony formation potential of the cells [22].

The genus Marrubium consists of approximately 50 species native to temperate regions of the world. The methanolic extract of the species Marrubium thessalum Boiss. \& Heldr from Olympus Mountain was tested against four commonly diagnosed cancer types: Breast adenocarcinoma MCF-7, cervix adenocarcinoma HeLa, colon carcinoma HCT116, and melanoma FM3. It was found to be more cytotoxic against HeLa cells, while exhibiting similar but lower cytotoxic potency in the other cell lines. In addition, the methanolic extract was also tested against human peripheral blood mononuclear cells (PBMCs) where it was found to be the most cytotoxic compared to some of its phenolic compounds (acteoside, leucosceptoside A, forsythoside B, alyssonoside, isoacteoside decaffeoyl-acteoside) indicating that it does not selectively kill cancer cells, in contrast to its components, which are promising agents for further studies [27].

Another member of the Lamiaceae family, the genus Ocimum consists of 30 species that are cultivated all around the world. Ocimum basilicum, also known as sweet basil, is one of the most popular food spices in the world and has been studied for its antimicrobial and pharmaceutical properties [56]. In 2014, the essential oil and ethanolic extract of sweet basil from Greece were studied for their action against the cervix adenocarcinoma HeLa, melanoma FemX, chronic myelogenous leukemia K562, and ovary adenocarcinoma SKOV3 cells lines [26]. The researchers observed that both extracts showed similar activity against SKOV3 and K562 cells, while the oil was two-fold more cytotoxic against HeLa and FemX cells. The oil exhibited the highest and similar activity against HeLa and FemX cells, followed by K562 and SKOV3. The ethanolic extract, on the other hand, was more cytotoxic against K562 cells, followed by HeLa, FemX, and SKOV3. Their activities were considered "mild but notable" compared to their main components. In general, with the exception of few cases, the components exhibited more significant activity and were considered to be responsible for the activity of the extracts. Those components were caffeic and rosmarinic acids for the ethanolic extract and eugenol and isoeugenol for sweet basil oil. Furthermore, the chemical composition of basil oil together with the essential oils isolated from the plants Fortunella margarita (kumquat), Mentha spicata (spearmint), and Pimpinella anisum (anise) was analyzed and their biological properties (antimicrobial, antioxidant, antiproliferative) were determined [25]. All of these plants are widely used for culinary purposes in Greece and as flavorings in beverages, gums, ice creams, etc. None of the essential oils exhibited significant antioxidant activity in vitro, whereas their cytotoxicity depended on the cell line used (HepG2, MCF-7, Caco2, THP-1). In general, sweet basil oil was the most cytotoxic against most of the cancer preclinical models used in the study, while kumquat and anise oils were the most efficient 
against THP-1 cells. Spearmint oil demonstrated an intermediate effect and it was the least cytotoxic against THP-1 cells.

\section{Conclusions}

Cancer incidence and mortality are constantly increasing, and novel strategies are required for its prevention and treatment. Products of natural origin have been used for their medicinal properties since ancient times and in the last years interest in these properties has increased. Currently, numerous studies exist investigating their pharmaceutical potential, including their chemopreventive and chemotherapeutic effect. Although the number of aromatic plant extracts of Greek origin that have been studied for their antiproliferative activity is limited, existing data against several cancer types are promising and encourage further exploitation of the country's unique flora diversity. Undoubtedly, further exploration of the molecular mechanisms of action of the extracts and their components is required not only in vitro but in vivo as well, to verify and establish their activity for their future use in the battle against cancer.

Author Contributions: Conceptualization, E.F. and A.P.; Investigation, Collecting sources of information, E.F, Writing-Original Draft Preparation E.F.; Writing-Review \& Editing, A.P.; Supervision, A.P.; Funding acquisition, A.P.

Funding: We acknowledge support of this work by the project «OPENSCREEN-GR: An Open-Access Research Infrastructure of Target-Based Screening Technologies and Chemical Biology for Human and Animal Health, Agriculture and Environment» (MIS 5002691) which is implemented under the Action "Reinforcement of the Research and Innovation Infrastructure", funded by the Operational Programme "Competitiveness, Entrepreneurship and Innovation" (NSRF 2014-2020) and co-financed by Greece and the European Union (European Regional Development Fund).

Conflicts of Interest: The authors declare no conflict of interest.

\section{References}

1. Svoboda, K.; Greenaway, R. Investigation of volatile oil glands of Satureja hortensis L. (summer savory) and phytochemical comparison of different varieties. Int. J. Aromather. 2003, 13, 196-202. [CrossRef]

2. Commission of the European Communities. Council Directive 92/43/EEC of 21 May 1992 on the conservation of natural habitats and of wild fauna and flora. Off. J. Eur. Communities 1992, 206, 7-50.

3. Dimopoulos, P.; Raus, T.; Bergmeier, E.; Constantinidis, T.; Iatrou, G.; Kokkini, S.; Strid, A.; Tzanoudakis, D. Vascular plants of Greece: An annotated checklist. Supplement. Willdenowia 2016, 46, 301-347. [CrossRef]

4. Kantsa, A.; Sotiropoulou, S.; Vaitis, M.; Petanidou, T. Plant Volatilome in Greece: A Review on the Properties, Prospects, and Chemogeography. Chem. Biodivers. 2015, 12, 1466-1480. [CrossRef] [PubMed]

5. Bray, F.; Ferlay, J.; Soerjomataram, I.; Siegel, R.L.; Torre, L.A.; Jemal, A. Global cancer statistics 2018: GLOBOCAN estimates of incidence and mortality worldwide for 36 cancers in 185 countries. CA Cancer J. Clin. 2018, 68, 394-424. [CrossRef] [PubMed]

6. OECD/European Observatory on Health Systems and Policies. Greece: Country Health Profile 2017, State of Health in the EU; Paris/European Observatory on Health Systems and Policies: Brussels, Belgium, 2017.

7. Ferlay, J.; Colombet, M.; Soerjomataram, I.; Dyba, T.; Randi, G.; Bettio, M.; Gavin, A.; Visser, O.; Bray, F. Cancer incidence and mortality patterns in Europe: Estimates for 40 countries and 25 major cancers in 2018. Eur. J. Cancer 2018, 103, 356-387. [CrossRef]

8. Bamia, C. Dietary patterns in association to cancer incidence and survival: Concept, current evidence, and suggestions for future research. Eur. J. Clin. Nutr. 2018, 72, 818-825. [CrossRef]

9. Stewart, B.; Wild, C. (Eds.) World Cancer Report 2014; International Agency for Research on Cancer: Lyon, France, 2014.

10. World Cancer Research Fund and American Institute for Cancer Research. Whole Grains, Vegetables and Fruit and the Risk of Cancer. Available online: https://www.wcrf.org/sites/default/files/Wholegrains-vegand-fruit.pdf (accessed on 6 August 2019). 
11. Karageorgou, D.; Magriplis, E.; Mitsopoulou, A.V.; Dimakopoulos, I.; Bakogianni, I.; Micha, R.; Michas, G.; Chourdakis, M.; Ntouroupi, T.; Tsaniklidou, S.M.; et al. Dietary patterns and lifestyle characteristics in adults: Results from the Hellenic National Nutrition and Health Survey (HNNHS). Public Health 2019, 171, 76-88. [CrossRef]

12. Trichopoulou, A.; Costacou, T.; Bamia, C.; Trichopoulos, D. Adherence to a Mediterranean diet and survival in a Greek population. N. Engl. J. Med. 2003, 348, 2599-2608. [CrossRef]

13. Buriani, A.; Fortinguerra, S.; Sorrenti, V.; Dall'Acqua, S.; Innocenti, G.; Montopoli, M.; Gabbia, D.; Carrara, M. Human Adenocarcinoma Cell Line Sensitivity to Essential Oil Phytocomplexes from Pistacia Species: A Multivariate Approach. Molecules 2017, 22, 1336. [CrossRef]

14. Loutrari, H.; Magkouta, S.; Pyriochou, A.; Koika, V.; Kolisis, F.N.; Papapetropoulos, A.; Roussos, C. Mastic oil from Pistacia lentiscus var. chia inhibits growth and survival of human K562 leukemia cells and attenuates angiogenesis. Nutr. Cancer 2006, 55, 86-93. [CrossRef] [PubMed]

15. Loutrari, H.; Magkouta, S.; Papapetropoulos, A.; Roussos, C. Mastic oil inhibits the metastatic phenotype of mouse lung adenocarcinoma cells. Cancers 2011, 3, 789-801. [CrossRef] [PubMed]

16. Magkouta, S.; Stathopoulos, G.T.; Psallidas, I.; Papapetropoulos, A.; Kolisis, F.N.; Roussos, C.; Loutrari, H. Protective effects of mastic oil from Pistacia lentiscus variation chia against experimental growth of lewis lung carcinoma. Nutr. Cancer 2009, 61, 640-648. [CrossRef] [PubMed]

17. Moulos, P.; Papadodima, O.; Chatziioannou, A.; Loutrari, H.; Roussos, C.; Kolisis, F.N. A transcriptomic computational analysis of mastic oil-treated Lewis lung carcinomas reveals molecular mechanisms targeting tumor cell growth and survival. BMC Med. Genomics 2009, 2, 68. [CrossRef] [PubMed]

18. Spyridopoulou, K.; Tiptiri-Kourpeti, A.; Lampri, E.; Fitsiou, E.; Vasileiadis, S.; Vamvakias, M.; Bardouki, H.; Goussia, A.; Malamou-Mitsi, V.; Panayiotidis, M.I.; et al. Dietary mastic oil extracted from Pistacia lentiscus var. chia suppresses tumor growth in experimental colon cancer models. Sci. Rep. 2017, 7, 3782. [CrossRef]

19. Balan, K.V.; Prince, J.; Han, Z.; Dimas, K.; Cladaras, M.; Wyche, J.H.; Sitaras, N.M.; Pantazis, P. Antiproliferative activity and induction of apoptosis in human colon cancer cells treated in vitro with constituents of a product derived from Pistacia lentiscus L. var. chia. Phytomedicine 2007, 14, 263-272. [CrossRef] [PubMed]

20. Balan, K.V.; Demetzos, C.; Prince, J.; Dimas, K.; Cladaras, M.; Han, Z.; Wyche, J.H.; Pantazis, P. Induction of apoptosis in human colon cancer HCT116 cells treated with an extract of the plant product, Chios mastic gum. In Vivo 2005, 19, 93-102.

21. Dimas, K.; Hatziantoniou, S.; Wyche, J.H.; Pantazis, P. A mastic gum extract induces suppression of growth of human colorectal tumor xenografts in immunodeficient mice. In Vivo 2009, 23, 63-68.

22. Giakoumettis, D.; Pourzitaki, C.; Vavilis, T.; Tsingotjidou, A.; Kyriakoudi, A.; Tsimidou, M.; Boziki, M.; Sioga, A.; Foroglou, N.; Kritis, A. Calpain-Dependent Death in C6 Rat Glioma Cells, Exhibiting a Synergistic Effect with Temozolomide. Nutr. Cancer 2019, 71, 491-507. [CrossRef]

23. Fitsiou, E.; Mitropoulou, G.; Spyridopoulou, K.; Vamvakias, M.; Bardouki, H.; Galanis, A.; Chlichlia, K.; Kourkoutas, Y.; Panayiotidis, M.; Pappa, A. Chemical Composition and Evaluation of the Biological Properties of the Essential Oil of the Dietary Phytochemical Lippia citriodora. Molecules 2018, 23, 123. [CrossRef]

24. Mitropoulou, G.; Fitsiou, E.; Spyridopoulou, K.; Tiptiri-Kourpeti, A.; Bardouki, H.; Vamvakias, M.; Panas, P.; Chlichlia, K.; Pappa, A.; Kourkoutas, Y. Citrus medica essential oil exhibits significant antimicrobial and antiproliferative activity. LWT Food Sci. Technol. 2017. [CrossRef]

25. Fitsiou, E.; Mitropoulou, G.; Spyridopoulou, K.; Tiptiri-Kourpeti, A.; Vamvakias, M.; Bardouki, H.; Panayiotidis, M.; Galanis, A.; Kourkoutas, Y.; Chlichlia, K.; et al. Phytochemical Profile and Evaluation of the Biological Activities of Essential Oils Derived from the Greek Aromatic Plant Species Ocimum basilicum, Mentha spicata, Pimpinella anisum and Fortunella margarita. Molecules 2016, 21, 1069. [CrossRef] [PubMed]

26. Zarlaha, A.; Kourkoumelis, N.; Stanojkovic, T.; Kovala-Demertzi, D. Cytotoxic Activity Of Essential oil and Extracts of Ocimum Basilicum Against Human Carcinoma Cells. Molecular Docking Study of Isoeugenol as a Potent Cox and Lox Inhibitor. Dig. J. Nanomater. Biostructures (DJNB) 2014, 9, 907-917.

27. Argyropoulou, A.; Samara, P.; Tsitsilonis, O.; Skaltsa, H. Polar constituents of Marrubium thessalum Boiss. \& Heldr. (Lamiaceae) and their cytotoxic/cytostatic activity. Phytother. Res. 2012, 26, 1800-1806. [CrossRef] [PubMed]

28. Fitsiou, E.; Anestopoulos, I.; Chlichlia, K.; Galanis, A.; Kourkoutas, I.; Panayiotidis, M.I.; Pappa, A. Antioxidant and Antiproliferative Properties of the Essential Oils of Satureja thymbra and Satureja parnassica and their Major Constituents. Anticancer Res. 2016, 36, 5757-5763. [CrossRef] [PubMed] 
29. Sivropoulou, A.; Papanikolaou, E.; Nikolaou, C.; Kokkini, S.; Lanaras, T.; Arsenakis, M. Antimicrobial and cytotoxic activities of Origanum essential oils. J. Agric. Food Chem. 1996, 44, 1202-1205. [CrossRef]

30. Spyridopoulou, K.; Fitsiou, E.; Bouloukosta, E.; Tiptiri-Kourpeti, A.; Vamvakias, M.; Oreopoulou, A.; Papavassilopoulou, E.; Pappa, A.; Chlichlia, K. Extraction, Chemical Composition, and Anticancer Potential of Origanum onites L. Essential Oil. Molecules 2019, 24, 2612. [CrossRef] [PubMed]

31. Mitropoulou, G.; Fitsiou, E.; Stavropoulou, E.; Papavassilopoulou, E.; Vamvakias, M.; Pappa, A.; Oreopoulou, A.; Kourkoutas, Y. Composition, antimicrobial, antioxidant, and antiproliferative activity of Origanum dictamnus (dittany) essential oil. Microb. Ecol. Health Dis. 2015, 26, 26543. [PubMed]

32. Marrelli, M.; Conforti, F.; Formisano, C.; Rigano, D.; Arnold, N.A.; Menichini, F.; Senatore, F. Composition, antibacterial, antioxidant and antiproliferative activities of essential oils from three Origanum species growing wild in Lebanon and Greece. Nat. Prod. Res. 2016, 30, 735-739. [CrossRef]

33. Chinou, I.; Liolios, C.; Moreau, D.; Roussakis, C. Cytotoxic activity of Origanum dictamnus. Fitoterapia 2007, 78, 342-344. [CrossRef]

34. Kaliora, A.C.; Kogiannou, D.A.; Kefalas, P.; Papassideri, I.S.; Kalogeropoulos, N. Phenolic profiles and antioxidant and anticarcinogenic activities of Greek herbal infusions; balancing delight and chemoprevention? Food Chem. 2014, 142, 233-241. [CrossRef] [PubMed]

35. Sarrou, E.; Giassafaki, L.P.; Masuero, D.; Perenzoni, D.; Vizirianakis, I.S.; Irakli, M.; Chatzopoulou, P.; Martens, S. Metabolomics assisted fingerprint of Hypericum perforatum chemotypes and assessment of their cytotoxic activity. Food Chem. Toxicol. 2018, 114, 325-333. [CrossRef] [PubMed]

36. Skalkos, D.; Stavropoulos, N.E.; Tsimaris, I.; Gioti, E.; Stalikas, C.D.; Nseyo, U.O.; Ioachim, E.; Agnantis, N.J. The lipophilic extract of Hypericum perforatum exerts significant cytotoxic activity against T24 and NBT-II urinary bladder tumor cells. Planta Med. 2005, 71, 1030-1035. [CrossRef] [PubMed]

37. Couladis, M.; Badisa, R.B.; Baziou, P.; Chaudhuri, S.K.; Pilarinou, E.; Verykokidou, E.; Harvala, C. Antioxidant and cytotoxic activities of Hypericum sp. on brine shrimps and human cancer cell lines. Phytother. Res. 2002, 16, 719-722. [CrossRef] [PubMed]

38. Menichini, F.; Conforti, F.; Rigano, D.; Formisano, C.; Piozzi, F.; Senatore, F. Phytochemical composition, anti-inflammatory and antitumour activities of four Teucrium essential oils from Greece. Food Chem. 2009, 115, 679-686. [CrossRef]

39. Kogiannou, D.A.; Kalogeropoulos, N.; Kefalas, P.; Polissiou, M.G.; Kaliora, A.C. Herbal infusions; their phenolic profile, antioxidant and anti-inflammatory effects in HT29 and PC3 cells. Food Chem. Toxicol. 2013, 61, 152-159. [CrossRef] [PubMed]

40. Badisa, R.B.; Tzakou, O.; Couladis, M.; Pilarinou, E. Cytotoxic activities of some Greek Labiatae herbs. Phytother. Res. 2003, 17, 472-476. [CrossRef] [PubMed]

41. Arias, B.A.; Ramón-Laca, L. Pharmacological properties of citrus and their ancient and medieval uses in the Mediterranean region. J. Ethnopharmacol. 2005, 97, 89-95. [CrossRef]

42. Quirantes-Piné, R.; Herranz-López, M.; Funes, L.; Borrás-Linares, I.; Micol, V.; Segura-Carretero, A.; Fernández-Gutiérrez, A. Phenylpropanoids and their metabolites are the major compounds responsible for blood-cell protection against oxidative stress after administration of Lippia citriodora in rats. Phytomedicine 2013, 20, 1112-1118. [CrossRef]

43. Pascual, M.E.; Slowing, K.; Carretero, E.; Sánchez Mata, D.; Villar, A. Lippia: Traditional uses, chemistry and pharmacology: A review. J. Ethnopharmacol. 2001, 76, 201-214. [CrossRef]

44. Chorianopoulos, N.; Kalpoutzakis, E.; Aligiannis, N.; Mitaku, S.; Nychas, G.-J.; Haroutounian, S.A. Essential oils of Satureja, Origanum, and Thymus species: Chemical composition and antibacterial activities against foodborne pathogens. J. Agric. Food Chem. 2004, 52, 8261-8267. [CrossRef] [PubMed]

45. Chorianopoulos, N.G.; Lambert, R.J.; Skandamis, P.N.; Evergetis, E.T.; Haroutounian, S.A.; Nychas, G.J. A newly developed assay to study the minimum inhibitory concentration of Satureja spinosa essential oil. J. Appl. Microbiol. 2006, 100, 778-786. [CrossRef] [PubMed]

46. Ayvaz, A.; Sagdic, O.; Karaborklu, S.; Ozturk, I. Insecticidal activity of the essential oils from different plants against three stored-product insects. J. Insect Sci. 2010, 10, 21. [CrossRef] [PubMed]

47. Giweli, A.; Džamić, A.M.; Soković, M.; Ristić, M.S.; Marin, P.D. Antimicrobial and antioxidant activities of essential oils of Satureja thymbra growing wild in Libya. Molecules 2012, 17, 4836-4850. [CrossRef] [PubMed] 
48. Loizzo, M.R.; Tundis, R.; Menichini, F.; Saab, A.M.; Statti, G.A.; Menichini, F. Cytotoxic activity of essential oils from Labiatae and Lauraceae families against in vitro human tumor models. Anticancer Res. 2007, 27, 3293-3299. [PubMed]

49. Michaelakis, A.; Theotokatos, S.A.; Koliopoulos, G.; Chorianopoulos, N.G. Essential oils of satureja species: Insecticidal effect on Culex pipiens larvae (Diptera: Culicidae). Molecules 2007, 12, 2567-2578. [CrossRef] [PubMed]

50. Sharifi-Rad, M.; Varoni, E.M.; Iriti, M.; Martorell, M.; Setzer, W.N.; Del Mar Contreras, M.; Salehi, B.; Soltani-Nejad, A.; Rajabi, S.; Tajbakhsh, M.; et al. Carvacrol and human health: A comprehensive review. Phytother. Res. 2018, 32, 1675-1687. [CrossRef] [PubMed]

51. Vokou, D.; Katradi, K.; Kokkini, S. Ethnobotanical survey of Zagori (Epirus, Greece), a renowned centre of folk medicine in the past. J. Ethnopharmacol. 1993, 39, 187-196. [CrossRef]

52. Tepe, B.; Cakir, A.; Sihoglu Tepe, A. Medicinal Uses, Phytochemistry, and Pharmacology of Origanum onites (L.): A Review. Chem. Biodivers. 2016, 13, 504-520. [CrossRef] [PubMed]

53. Klemow, K.M.; Bartlow, A.; Crawford, J.; Kocher, N.; Shah, J.; Ritsick, M. Medical Attributes of St. John's Wort (Hypericum perforatum). In Herbal Medicine: Biomolecular and Clinical Aspects, 2nd ed.; Benzie, I.F.F., Wachtel-Galor, S., Eds.; CRC Press: Boca Raton, FL, USA, 2011.

54. José Bagur, M.; Alonso Salinas, G.L.; Jiménez-Monreal, A.M.; Chaouqi, S.; Llorens, S.; Martínez-Tomé, M.; Alonso, G.L. Saffron: An Old Medicinal Plant and a Potential Novel Functional Food. Molecules 2017, $23,30$. [CrossRef] [PubMed]

55. Leone, S.; Recinella, L.; Chiavaroli, A.; Orlando, G.; Ferrante, C.; Leporini, L.; Brunetti, L.; Menghini, L. Phytotherapic use of the Crocus sativus L. (Saffron) and its potential applications: A brief overview. Phytother. Res. 2018. [CrossRef] [PubMed]

56. Bower, A.; Marquez, S.; de Mejia, E.G. The Health Benefits of Selected Culinary Herbs and Spices Found in the Traditional Mediterranean Diet. Crit. Rev. Food Sci. Nutr. 2016, 56, 2728-2746. [CrossRef] [PubMed] 